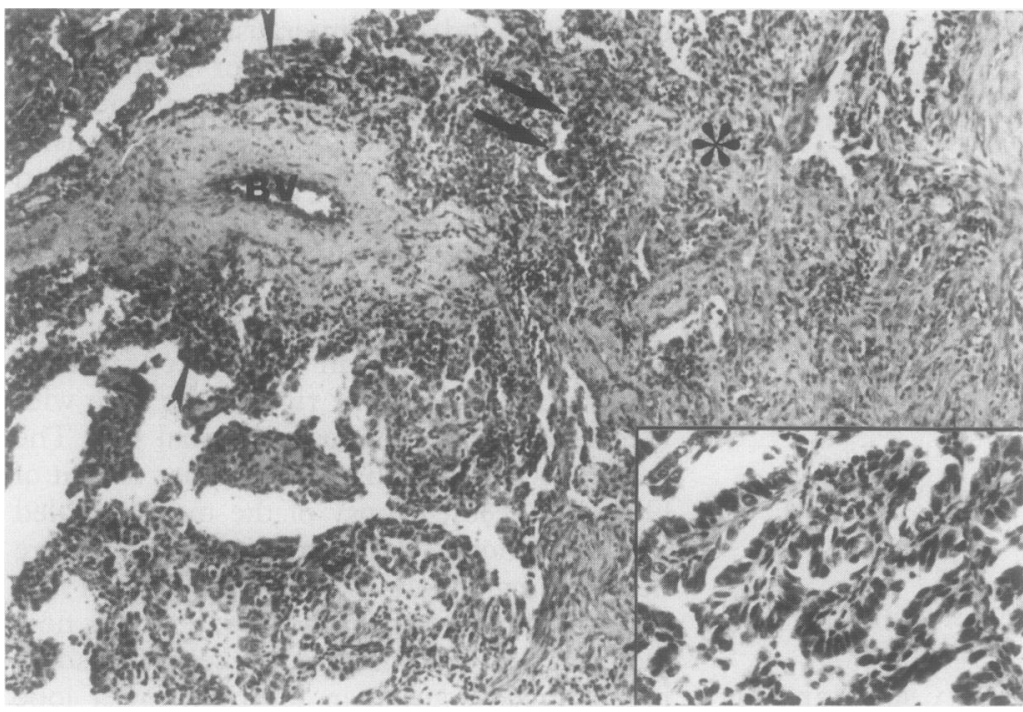

Figure 2 Tumour invading the pleura (*, arrows) and encroaching the blood vessel (BV, arrowheads). The tumour cells (insert) are columnar or cuboidal in shape and arranged in a typical bronchioloalveolar pattern. Stain: haemotoxylin and eosin.

tured" into the pleural cavity causing the haemothorax. The latter possibility appears likely as examination of the resected specimen showed a small perforation in the vis- ceral pleura which was covered by a fibrin clot, and microscopic examination revealed tumour invasion of the pulmonary vessels and visceral pleura (fig 2).

To our knowledge this is the first report of primary lung cancer causing haemothorax.

1 Calvent $\mathrm{RD}$, Smith E. An analytical review of haemopneumothorax. Thorax 1955;10:64-8.

2 DeMeester TR, Lafontaine E. The pleura. In: Sabiston DC, Spencer FC, eds. Surgery of the chest. 5th edn. New York: Saunders, 1990:444-97.

3 Abyholm FE, Storen G. Spontaneous hemopneumothorax. Thorax 1973;28:376-8.

4 DeFrance JH, Blewett JM, Ricci JA, Patterson LT. Massive hemothorax: two unusual cases. Chest 1974 66:1-3.

5 Johnson TR, Comstock CH, Anderson DG. Benign gestational trophoblastic disease metastatic to pleura: unusual cause of hemothorax. Obstet Gynecol 1979;53: 509-11.

6 Templeton PA, Vainright JR, Rodriguez A, Diaconis JN. Mediastinal tumors presenting as spontaneous hemothorax, simulating aortic aneurysm. Chest 1988;93:4-10.

7 Sudduth CD, Strange C, Campbell BA, Sahn SA Metastatic choriocarcinoma of the lung presenting as hemothorax. Chest 1991;99:2-3.

8 Lin HH, Liaw CT, Liaw YF. Hepatocellular carcinom presenting as acute spontaneous hemothorax. 7 Gastroenterol Hepatol 1990;5:362-4.

9 Reynolds JR, Morgun E. Hemothorax caused by a solitar costal exostosis. Thorax 1990;45:68-9.

Thorax 1993;48:1186-1187

\section{Need for a comparative performance standard for dry powder inhalers}

\author{
Robert Richards, Michael Saunders
}

\begin{abstract}
The efficacy of dry powder inhalers is dependent on the inspiratory flow rate at which they are used. The resistance to airflow through five different dry powder inhaler devices was measured. The devices were shown to vary significantly, with the Turbohaler having the highest resistance. We suggest that the performance of dry powder inhalers should be assessed at comparable pressure drops producing clinically relevant inspiratory flow rates for each device.
\end{abstract}

(Thorax 1993;48:1186-1187)

Department of
Respiratory Medicine,
Llandough Hospital,
Cardiff CF6 1XX
R Richards
M Saunders
Reprint requests to:
Dr R Richards
Received 21 July 1992
Returned to authors
15 September 1992
Revised version received
25 November 1992
Accepted 16 February 1993

There are now five types of dry powder inhaler (DPI) available for prescription in the United Kingdom. At present there is no measure of performance by which comparisons of DPIs can be made and no official guidelines have been published.

Most DPIs are sensitive to inspiratory flow rate, the higher the flow rate the greater the efficacy of drug delivery. ${ }^{1-4}$ All standard pulmonary function tests are poor predictors of the inspiratory flow rate that patients can generate through these devices. ${ }^{5}$ To demonstrate the wide differences between the devices we have measured the resistance of the Turbohaler, Diskhaler (four and eight place), Rotahaler, and Spinhaler.

\section{Methods}

The resistance of each DPI was assessed using a static tube and water manometer employing the method described by Cotes $^{6}$ (fig 1). Each DPI was loaded and actuated as described in the written instructions and then attached to one end of the static tube. The air flow was generated by an electrically driven blower, adjusted via a choke valve, and measured by a rotameter. One end of a water manometer was inserted into the static tube with the other end being open to the atmosphere, enabling the pressure drop caused by each device to be measured at specific flow rates. Each device was assessed from $101 / \mathrm{min}$ with increasing increments of 10 to a maximum of $100 \mathrm{l} / \mathrm{min}$. Three measurements were made at each flow rate for each device. Differences between the data points were assessed by analysis of variance.

\section{Results}

Each device has its own pressure/flow characteristics (fig 2). Variation in the measurements were minimal with all standard deviations being under $12 \mathrm{~mm} \mathrm{H}_{2} \mathrm{O}$. The device with the least resistance was the Spinhaler which, at $60 \mathrm{l} / \mathrm{min}$, had a mean (SD) deflection of only $35(0.58) \mathrm{mm} \mathrm{H}_{2} \mathrm{O}$. All the other devices had significantly greater 


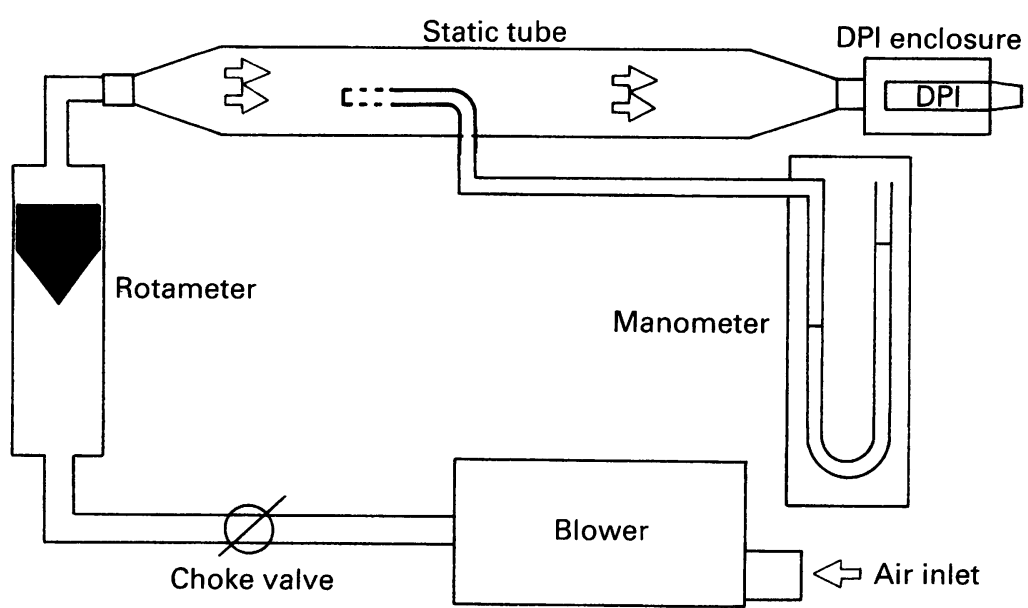

Figure 1 The device used to compare the pressure drop across the dry powder inhalers. Adapted from Cotes. ${ }^{6}$ choosing a DPI for a patient one is faced with a wide choice. It is possible to deliver both $\beta_{2}$ agonists and corticosteroids via three types of DPI (Rotahaler and Diskhaler (eight place): Allen and Hanburys Ltd; Turbohaler: Astra Pharmaceuticals $\mathrm{Ltd}$ ). If the performance of these devices was assessed at $60 \mathrm{l} / \mathrm{min}$, as is the case for metered dose inhalers, ${ }^{7}$ the wrong impression would be given as to their function in the clinical setting. To achieve $60 \mathrm{l} / \mathrm{min}$ through a Turbohaler would take nearly three times the effort needed for the eight place Diskhaler (264 $\mathrm{mm} \mathrm{H}_{2} \mathrm{O} v 90 \mathrm{~mm}$ $\mathrm{H}_{2} \mathrm{O}$ ). Comparable data on these devices would be best obtained at a series of constant pressure drops-for example, at 100 and 200 $\mathrm{mm} \mathrm{H}_{2} \mathrm{O}$-thereby providing a guide to the relative performance in clinical practice. For example, a patient who could achieve an inspiratory flow rate of $35 \mathrm{l} / \mathrm{min}$ through a Turbohaler could manage over $80 \mathrm{l} / \mathrm{min}$ via a Rotahaler; at present we do not know which device would be the more effective at these flow rates. Adoption of this form of testing would take into account the greater inertial impaction produced at high flow rates as the specific flow rate used would be similar to that produced in the clinical setting. However, impaction is probably of less importance than the raw inspiratory flow rate, as we have shown previously that flow rates of up to $300 \mathrm{l} / \mathrm{min}$ produce both superior drug delivery and protection when using the Spinhaler. ${ }^{12}$

In the case of $\beta_{2}$ agonists it is usually obvious if a particular device is ineffective in an individual patient. However, we are more concerned with the use of corticosteroid DPIs where no immediate feedback is given as to the efficacy of the inhalation. It is therefore important that data be provided by the manufacturers of these devices so that useful comparisons can be made and the right device can be prescribed for the individual patient.

resistances at flow rates above 20 $(\mathrm{p}<0.01)$ than the Spinhaler, with the Turbohaler having the highest (fig 2). In practice a patient would have to be capable of much higher pressures to achieve these flow rates, so they cannot be directly translated into values for maximum inspiratory pressures and are therefore suitable for comparative purposes only.

\section{Discussion}

We have shown a wide variation in the resistances of DPIs. It is probable that the dispersion of the powder into an aerosol is dependent on the turbulence created by the DPI and not the absolute flow rate, but for each device the turbulence would be proportional to the inspiratory flow rate. When
1 Richards R, Simpson S, Renwick AG, Holgate ST. Inhalation rate of sodium cromoglycate determines plasma pharmacokinetics and protection against AMPinduced bronchoconstriction in asthma. Eur Respir 1988;1:896-901.

2 Richards R, Dickson CR, Renwick AG, Holgate ST. The absorption and disposition kinetics of cromolyn sodium and the influence of inhalation technique. $\boldsymbol{f}$ Pharmacol Exp Ther 1987;241:1028-32.

3 Pedersen S, Hansen OR, Fuglsang G. Influence of inspiratory flow rate upon the effect of a Turbohaler. Arch Dis Child 1990;65:308-19.

4 Pedersen S. How to use a Rotahaler. Arch Dis Child 1986;61:11-4.

5 Engel R, Heinig JH, Madsen F, Nikander K. Peak inspiratory flow and inspiratory vital capacity of patients with asthma measured with and without a new dry-powder inhaler device. Eur Respir F 1990;3:1037-41.

6 Cotes JE. Lung function. 3rd ed. Oxford: Blackwell 1975:28-9.

7 British Pharmacopoeia. Pressurised inhalations: deposition of the emitted dose. Appendix XVII: A204-A207. 